\title{
LA ADMINISTRACION PERIFERICA EN EL ESTADO DE LAS AUTONOMIAS
}

(Conferencia pronunciada en la sesión de clausura del Curso de perfeccionamiento para Funcionarios, celebrado en Santa Cruz de Tenerife, noviembre-diciembre 1988)

\author{
POR \\ MarTín Orozco MuÑoz
}

Abogado del Estado

SUMARIO: I. InTRODUCCIÓN.-II. Configuración CONSTItUCIONAL.-III. ReEstruCTURACIÓN DE LA ADMINISTRACIÓN PERIFÉRICA DEL EstADO: A) Criterios apriorísticos que han de informar la reestructuración de la Administración periférica del Estado; B) Reseña de las medidas y reestructuración realizadas.-IV. PRINCIPALES LíneAs DE REFORMA: A) Ubicación territorial de la Administración periférica: ¿provincialización o regionalización?; B) Coexistencia y relación entre el Delegado del Gobierno y el Gobernador civil; C) Configuración de las unidades departamentales periféricas.

\section{INTRODUCCION}

Tras la Constitución de 1978 se opera en nuestro Estado una reestructuración esencial en la organización político-territorial del mismo que deriva en una nueva forma de Estado, a la que nuestro Tribunal Constitucional, innovando las clasificaciones clásicas acuñadas por la llamada «morfología política», ha denominado como "Estado de las Autonomías». Prescindiendo de disquisiciones teóricas sobre la naturaleza de esta nueva organización territorial, cabe afirmar, siguiendo al Profesor Lucas Verdú, que la Constitución ha operado una auténtica refundación del Estado, en la medida de que partiendo de un mismo pueblo y de un mismo territorio, $y$ operando con poder soberano, se ha configurado mediante normas e instituciones jurídico-públicas la nueva estructuración del Estado en base a una configuración autonómica.

La descentralización política operada ha de afectar necesariamente al ámbito competencial $y$ organizativo de la estructura central del Estado, en base al vaciamiento de atribuciones que sobre la misma se opera en beneficio de las Comunidades Autónomas, a las que se dota de autonomía política (arts. 2 y 137 de la Constitución Española) con la consiguiente asunción de competencias y dotación de una propia estructura organizativo-administrativa. 
Centrándonos exclusivamente a las incidencias que tal descentralización produce en cuanto a las competencias ejecutivas $y$ administrativas ejercidas hasta la promulgación de la Constitución por el Estado central, procede analizar sucintamente cuál ha sido la fórmula seguida al respecto en los sistemas federales contemporáneos, y que, siguiendo al Profesor Muñoz Machado, podemos concretar en los dos siguientes:

a) Sistemas en los que las competencias de ejecución pertenecen al mismo ente, central o autonómico, que haya dictado la norma cuya ejecución se pretende, con lo cual es necesario el mantenimiento de una organización administrativa periférica dependiente del poder central, y de otros tantos aparatos administrativos como entes autonómicos existan.

b) Sistemas en los que la totalidad de las competencias ejecutivas son asumidas por los entes autonómicos, con independencia de cuál sea el origen, central o autonómico, de la norma a ejecutar, con la consecuencia lógica de la desaparición del aparato administrativo periférico dependiente del poder central y la asunción de la función administrativa global por la Administración propia de los entes autonómicos o Estados miembros. Dentro de este sistema cabe, a su vez, distinguir los modelos en los que la Administración autonómica cuenta con plena autonomía en su gestión, de aquéllos, como el austríaco, en los que, como afirma el Profesor García de Enterría, la ejecución de la legislación federal o estatal por los "Länder» es considerada como "Administración federal indirecta», subordinada jerárquicamente al poder central o estatal. En cualquier caso, la globalidad de este sistema constituye lo que la doctrina ha venido denominando el ufederalismo de ejecución»».

\section{CONFIGURACION CONSTITUCIONAL}

A la vista de los sistemas comparados existentes en los Estados en los que rige una descentralización política relevante, cabe cuestionarnos cuál es la solución prevista en nuestro texto constitucional. En tal sentido, procede afirmar la existencia de dos principios constitucionales básicos que inspiran la configuración de la Administración del Estado en el nuevo régimen autonómico:

1. La consagración orgánica y funcional de la existencia necesaria de la Administración del Estado, tanto a nivel periférico como central; $y$

2. La necesidad obligada de reestructuración de la misma. 
En cuanto al primer principio mencionado, viene fundamentado, como indicamos, desde una doble perspectiva, funcional y orgánica, que pasamos a exponer:

a) Funcionalmente, si nos ceñimos al reparto competencial que opera la Constitución en cuanto a las facultades ejecutivas entre el Estado y las Comunidades Autónomas, si bien cabe señalar, como regla general, la atribución masiva a estas últimas de las competencias ejecutivas tanto en materia cuya legislación corresponde a las mismas (art. 148.1), como en aquéllas en que el Estado se reserva la competencia normativa, «sin perjuicio de su ejecución por las Comunidades Autónomas» (reconocidas a lo largo de la lista contenida en el art. 149.1 de la C.E.), no cabe duda, sin embargo, del reconocimiento al Estado de un importante elenco de competencias de ejecución, que, resumidamente, podemos concretar en las siguientes:

Materias en las que el Estado ostenta competencia plena, tanto normativa como ejecutiva, reconocidas en el ámbito del artículo 149.1 de la C.E., pudiendo citarse entre otras las relativas a nacionalidad, extranjería, relaciones internacionales, defensa, justicia, régimen aduanero, etc.

Competencias de ejecución reservadas al Estado en base al carácter suprarregional de la actividad o a su incidencia en el «interés general» (v.gr., "transportes terrestres que transcurran por el territorio de más de una Comunidad Autónoma», "aprovechamientos hidráulicos cuando las aguas discurran por más de una Comunidad Autónoma», "puertos de interés general», "aeropuertos de interés general», etc.).

Competencias de ejecución no asumidas por las Comunidades Autónomas en sus propios Estatutos, que corresponden al Estado en base a la cláusula residual de segundo grado contenida en el artículo 149.3 de la C.E.

Competencias ejecutivas implícitas reconocidas por el Tribunal Constitucional y que, siguiendo a García de Enterría, podemos concretar en los supuestos de razones de urgencia o situaciones excepcionales en materia de orden público o salud pública (STC 8 junio 1982) que exijan una actuación inmediata y provisional; situaciones de ejecución inter o supraterritorial (STC 28 enero 1981), y, finalmente, los supuestos en que el Estado retiene facultades ejecutivas de la legislación básica, cuya competencia le corresponde, cuando el contenido material de esas bases resulta inseparable de la fase de ejecución (STC 22 febrero 1982).

b) Orgánicamente, cabe plantear si pese a la existencia del ámbito competencial de ejecución indicado es factible la supresión 
de la Administración del Estado en el ámbito periférico, asumiendo tales competencias periféricas órganos encuadrados en la Administración autonómica mediante las vías de transferencia y delegación contenidas en el artículo 105.2 de la C.E. Entendemos que la respuesta ha de ser negativa en base a los siguientes fundamentos jurídico-constitucionales:

1. El reconocimiento por la Constitución de la Administración del Estado al regular la figura del Gobierno (art. 97 y ss. de la C.E.), deduciéndose igualmente el reconocimiento de los Departamentos Ministeriales al tratar de la "competencia y responsabilidad directa de los Ministros en su gestión» (art. 97.2), afirmación básica a nuestros efectos por cuanto que viene a consagrar la estructura departamental estatal, en la que se integran tanto los órganos centrales como los periféricos.

2. La plasmación del principio de desconcentración, contenido en el artículo 103.1 de la C.E., cuya aplicación a la Administración del Estado, así como a toda la Administración pública, no sólo se proyecta sobre la «actuación administrativa», sino, obviamente, también sobre la propia estructura de la misma. En este sentido, el principio de desconcentración aboga claramente por el mantenimiento de un aparato administrativo periférico de la Administración estatal, por cuanto que:

- La desconcentración opera no sólo en un sentido horizontal, sino también, y sustancialmente, en un plano vertical, esto es, en favor de órganos desconcentrados territorialmente.

- De una interpretación histórica del precepto constitucional cabe deducir igualmente que si a la entrada en vigor de la Constitución preexistía una Administración estatal periférica la aplicación del principio de desconcentración impide el desmantelamiento de tal organización.

3. El reconocimiento de la provincia como «división territorial para el cumplimiento de las actividades del Estado», consagrado en el artículo 141.1 de la C.E., que exige la ubicación de los órganos administrativos a dicho nivel territorial básico.

4. El problema a plantear, tal como expusimos anteriormente, reside en si es compatible su plasmación con la atribución de las funciones estatales a ejecutar a nivel periférico a órganos propios de las Comunidades Autónomas, previa delegación o transferencia, cuestión que no queda contundentemente resuelta con las tres fundamentaciones anteriores, pudiendo traerse aquí la afirmación de Lozano Romeral, para quien la provincialización contenida en el artículo 141.1 de la C.E. citado queda asegurada situando a nivel provincial órganos administrativos de la Comunidad Autónoma a la 
que se haya transferido o delegado las competencias estatales de ejecución. Sin embargo, entiendo que tal cuestión queda definitivamente resuelta al amparo del artículo 154 de la Constitución, a cuyo tenor:

«Un Delegado nombrado por el Gobierno dirigirá la Administración del Estado en el territorio de la Comunidad Autónoma y la coordinará, cuando proceda, con la administración propia de la Comunidad.»

De dicho precepto cabe deducir, con claridad, el reconocimiento expreso a nivel orgánico de la Administración periférica del Estado, en base a los siguientes fundamentos:

- Se institucionaliza la figura del Delegado del Gobierno, en cuanto órgano periférico de la Administración estatal, de carácter básico y constitucionalmente necesario.

- Se configura como "objeto» de la dirección a desempeñar por el Delegado del Gobierno, a la «Administración del Estado en el territorio de la Comunidad Autónoma», término éste que debe entenderse: $1 .^{\circ}$ ) Como Administración en sentido orgánico, esto es, como estructura de órganos sometidos a la dirección del Delegado del Gobierno, frente a la expresión funcional contenida en el artículo 124 de la Constitución italiana, que proyecta la actuación directiva del Comisario del Gobierno sobre las funzioni amministrative esercitate dallo Stato; $\left.2 .^{\circ}\right)$ como Administración del Estado, en cuanto complejo de órganos con dependencia orgánica y funcional exclusivamente estatal, y $3 .^{\circ}$ ) Como Administración del Estado periférica, "situada en el territorio de la Comunidad Autónoma». Con ello se reconoce ineludiblemente la existencia necesaria de una organización periférica estatal, exigencia que habrá de vincular a cualquier intento de reorganización administrativa que en el futuro pudiera plantearse.

- La función coordinadora del Delegado del Gobierno constituye una actividad relacional, que se proyecta sobre dos polos de actuación distintos, por la propia naturaleza del principio de coordinación, uno de los cuales ha de ser la actividad administrativa estatal desempeñada básicamente por los órganos periféricos, constituyendo el otro la administración autonómica respectiva.

Analizada la configuración orgánico-funcional de la Administración del Estado en la Constitución de 1978, procede ahora abordar el análisis del segundo gran principio constitucional que, en nuestra 
opinión, ha de vincular toda actuación sobre la materia, cual es el de la necesaria reestructuración de dicha organización administrativa, ciñendo nuestro estudio al nivel periférico.

\section{REESTRUCTURACION DE LA ADMINISTRACION PERIFERICA DEL ESTADO}

Tal como apuntamos al comienzo del presente trabajo, la configuración del «Estado de las Autonomías» opera necesariamente sobre las estructuras administrativas preexistentes, en base a la descentralización política y administrativa que en su detrimento competencial se ha llevado a efecto, derivando como consecuencia la necesidad de replantear su organización preconstitucional, con la finalidad de acomodarla al nuevo plano jurídico-político. El análisis de esta reestructuración lo haremos señalando, en primer lugar, los criterios apriorísticos que han de inspirarla, para después concretar las reformas realizadas, concluyendo finalmente con la fijación de las pautas que, en nuestra opinión, deben informar la reestructuración pretendida (cuestión esta que abordaremos en la última parte de esta comunicación).

\section{A) Criterios aprioristicos que han de informar la reestructura- ción de la Administración periférica del Estado}

Podemos concretarlos en los tres siguientes:

1. Vinculatoriedad de los principios y preceptos constitucionales.-Como afirma el profesor García de Enterría, los preceptos orgánicos constitucionales son de inmediata aplicación por todos los poderes públicos, en cuanto se refieran a la formación, competencias $y$ organización, de lo cual se deriva una eficacia organizatoria inmediata de la Constitución, que vincula al titular de la potestad organizatoria, tanto en sede legislativa como administrativa.

Sin embargo, no cabe duda que la configuración de principios constitucionales de organización, como son básicamente los contenidos en el artículo 103 de nuestra Norma Fundamental, no vienen más que a diseñar un «programa» organizativo que precisa de un desarrollo posterior con un gran margen de determinación y concreción práctica, lo cual dota de un importante grado de discrecionalidad a la potestad organizatoria, aunque enmarcado dentro de límites esenciales, como son:

a) La necesidad de una base legal habilitante, reconocida en el artículo 103 , párrafo $2 .^{\circ}$, de la C.E., al señalar que «los órganos de 
la Administración son creados, regidos y coordinados de acuerdo con la ley», y en el artículo $149.1 .18 .^{\circ}$ de la misma, y que ha tenido su plasmación práctica en la Ley del Proceso Autonómico, básicamente en la normativa programática contenida en su artículo 23 , y en la Ley 17/1983, de 16 de noviembre, sobre los Delegados del Gobierno, que, tal como dispone su Exposición de Motivos, regula "de forma definitiva y con el rango adecuado la figura del Delegado del Gobierno».

b) La aplicación inmediata de los preceptos organizativos directos, como son sustancialmente el reconocimiento de la provincia como división territorial para el cumplimiento de las actividades del Estado (art. 141.1) y la institucionalización de la figura del Delegado del Gobierno (art. 154), así como la necesariędad del mantenimiento de una Administración periférica del Estado (art. 154), en los términos ya analizados.

c) El control constitucional de la potestad organizatoria. Como afirma Sánchez Morón, el Tribunal Constitucional podría declarar la inconstitucionalidad de las instituciones administrativas existentes que vulneren los principios constitucionales; por su parte, Alvarez Rico concluye que los principios constitucionales del artículo 103.1 de la C.E. se pueden configurar como constitutivos de una legalidad material a la que se somete la potestad organizatoria de la Administración del Estado, junto a la legalidad formal prevista en el artículo 103.2 de la CE. En consecuencia, cabe afirmar que la vinculatoriedad de la Norma Constitucional en la materia organizatoria se aplica no sólo a los preceptos organizativos directos, sino también a los principios de tal carácter que en la misma se contienen, merced a su carácter informador, reconocido por la STC de 2 de febrero de 1981, lo cual permite el control de su plasmación por el Tribunal Constitucional, en cuanto intérprete supremo de la Constitución (art. 1.1 de la LOTC), así como por la Jurisdicción Contencioso-Administrativa, en su caso (al amparo de los arts. 1,5 y 6 de la LOPJ).

2. Concurrencia de elementos que dificultan la reestructuración.-Son diversos los supuestos que entorpecen notablemente el proceso de remodelación que analizamos, supuestos entre los que hay que distinguir aquellos que son consustanciales al propio sistema autonómico, que vamos a denominar elementos estructurales, y aquellos otros residuales o contingentes de factible superación:

a) Elementos estructurales; cabe señalar los siguientes:

- Configuración progresiva de la descentralización política aún no culminada.-La ya estudiada interdependencia entre el 
proceso autonómico y la reorganización administrativa estatal, produce que la configuración del primero incida sustancialmente en la segunda. En tal sentido, el carácter progresivo de la plasmación autonómica impide y ha impedido una reestructuración administrativa definitiva. Como afirma el profesor Lucas Verdú, la Constitución no establece un auténtico modelo de Estado, sino que deja la distribución territorial de competencias indeterminada; el Constituyente, con gran pragmatismo, prefirió prescindir de una formula precisa a priori para no comprometer el desarrollo posterior de la Constitución. Ello ha tenido como reflejo, en cuanto a la reorganización administrativa se refiere, los siguientes efectos inevitables: 1. Escalonamiento de las medidas reformadoras adoptadas; $2 .^{\circ}$ Transitoriedad de las mismas; $3 .^{\circ}$ Excesiva flexibilidad e inconcreción en la regulación de las nuevas figuras organizativas. Por todo ello, podemos hablar de una reestructuración comenzada, pero en modo alguno concluida e impregnada de una gran dosis de incertidumbre de futuro, que puede apreciarse con claridad meridiana en la Exposición de Motivos de la Ley $17 / 1983$, de 16 de noviembre, al señalar que dicha ley «no pretende condicionar la futura regulación de la Administración periférica del Estado que pueda resultar de la culminación del proceso de transferencias que debe llevarse a cabo de acuerdo con los Estatutos de Autonomía promulgados».

- Diferenciación del ámbito competencial entre las distintas Comunidades Autónomas.-La delimitación de diversos techos competenciales entre las Comunidades Autónomas, debido a la configuración de distintas vías de acceso a la autonomía (con el diferente elenco competencial inicial inherente a cada una de ellas), el carácter dispositivo de la asunción estatutaria de competencias, así como la diferente plasmación de los medios extraestatutarios de atribución competencial previstos en el artículo 150 de la C.E., determina, obviamente, que el residuo competencial reservado a la Administración periférica del Estado en cada Comunidad Autónoma sea distinto, e incida en su estructuración orgánica, impidiendo así una ubicación uniforme de dicha Administración en todo el territorio nacional.

- Diversa intensidad de competencias entre los distintos departamentos ministeriales, que produce como consecuencia: $1 .{ }^{\circ}$ La desaparición o reducción al mínimo exponente de la estructura periférica de determinados Departamentos (v.gr. Cultura y Educación y Ciencia), frente al mantenimiento 
de otros Ministerios con una estructura cuantitativa y cualitativamente relevante (v.gr. Ministerio de Economía y Hacienda); 2..$^{\circ}$ La distinta estructuración territorial del aparato periférico de los Departamentos, prevaleciendo en unos el nivel regional de ubicación y en otros el nivel provincial, aplicándose en determinados supuestos un nivel territorial supraprovincial pero infrarregional (v.gr. la Orden de 7 de febrero de 1986 configura dentro del MOPU dos Demarcaciones de Costas en Andalucía: "Andalucía-Atlántico» y "Andalucía-Mediterráneo»). Con todo ello se acredita la imposibilidad igualmente de una uniformidad orgánica interdepartamental, exigiéndose así una reestructuración sectorial que atienda a las peculiariedades de cada Departamento, en sí mismo considerado, y en relación al nivel competencial atribuido a las respectivas Comunidades Autónomas en que se asienten sus respectivos órganos periféricos.

b) Elementos residuales: Entre ellos cabe destacar la inercia de las instituciones y estructuras existentes a su permanencia, así como la tendencia de los departamentos ministeriales a mantener la dependencia directa de sus órganos periféricos, con lo que se limita de forma importante la coordinación unitaria de la actuación administrativa periférica a nivel provincial o regional, aspectos ambos puestos de manifiesto por la doctrina administrativa.

3. Vertientes sobre las que ha de operar la reestructuración. Cabe hablar de un triple ámbito de actuación: cuantitativo, cualitativo y territorial, que pasamos a enunciar:

a) Cuantitativamente, el vaciamiento competencial estatal ha de tener su traducción en la reducción o, en su caso, supresión de los servicios periféricos afectados por el traspaso de competencias que resulten innecesarios.

b) Cualitativamente, la asunción por el Estado de nuevas funciones de coordinación, supervisión, planificación e inspección, determinan la necesidad de conversión de las estructuras de gestión que resulten innecesarias en servicios encaminados $y$ configurados orgánicamente para el desempeño de tales funciones. Igualmente, el aspecto cualitativo ha de incidir en la ya iniciada reestructuración de las unidades administrativas departamentales residuales en cuanto a su acoplamiento orgánico.

c) El ámbito territorial, por su parte, se ha de centrar en la configuración de una ubicación territorial básica de la Administración periférica estatal, centrándose aquí la tan discutida opción entre la provincialización o regionalización. 


\section{B) Reseña de las medidas de reestructuración realizadas}

El ya tratado carácter evolutivo de la reforma administrativa, se ha plasmado, tras la Constitución, en distintas disposiciones normativas que podemos clasificar en dos grandes grupos:

a) Disposiciones tendentes a una reforma global o general de la Administración periférica, entre las que destacan:

Con carácter fundamental, y con un contenido programático en cuanto a la plasmación posterior de la reforma administrativa, cabe citar como norma básica la Ley del Proceso Autonómico, de 14 de octubre de 1983, que en su título $V$ («De reforma de la Administración») delimita:

1. Los principios constitucionales que han de inspirar la reforma, concretados en los de "eficacia, desconcentración, coordinación y economía del gasto público» (art. 22.1).

2. Los criterios y objetivos básicos a seguir, concretados en: a) La reorganización de los servicios periféricos de los departamentos ministeriales para acomodarlos a las funciones que subsistan b) Supresión de las delegaciones ministeriales y reagrupamiento de los servicios bajo la autoridad del Gobernador civil, "único delegado de la Administración del Estado en las provincias, estructurándose, por su parte, los servicios periféricos situados en el escalón regional bajo la autoridad del Delegado del Gobierno, y c) Supresión de las estructuras innecesarias de gestión y su reconversión en servicios de coordinación, planificación, inspección y documentación (art. 23).

Del articulado de esta Ley cabe reseñar una serie de características fundamentales, como son, en primer lugar, la previsión de medidas tanto cuantitativas como cualitativas, en los términos antes mencionados; en segundo lugar, el mantenimiento de dos representantes generales de la Administración del Estado a nivel periférico (Gobernadores civiles y Delegados del Gobierno); en tercer lugar, el reconocimiento del carácter "progresivo» de la reforma administrativa a realizar "para acomodar la estructura de la Administración del Estado a las exigencias del proceso autonómicon; y por último, la plasmación de algunos de sus principios con anterioridad a su entrada en vigor, destacándose así la supresión operada previamente de las delegaciones ministeriales.

Destaca en segundo lugar el Real Decreto 1801/1981, de 24 de julio, de Reforma de la Administración periférica del Estado, que articula la primera reforma posconstitucional de la Administración periférica, con carácter gradual pero de enorme trascendencia, 
señalando como notas más relevantes: 1. ${ }^{\circ}$ Integración de la Administración periférica por las Delegaciones del Gobierno y los Gobiernos Civiles; 2. ${ }^{\circ}$ Configuración de una Comisión de coordinación a nivel regional presidida por el Delegado del Gobierno; 3. Condición del Gobernador civil como representante del Gobierno de la Nación en la provincia, asumiendo la superior dirección de la Administración Civil del Estado en la misma, así como su coordinación; 4..$^{\circ}$ Supresión de las Delegaciones ministeriales e institucionalización de las Direcciones Provinciales Departamentales, caracterizadas por su integración en el Gobierno Civil respectivo, bajo la autoridad del Gobernador y con dependencia orgánica y funcional del respectivo Ministerio, asumiendo la gestión y ejecución de la política del Gobierno en el sector correspondiente; flexibilizándose igualmente su estructuración al permitirse, de un lado, la creación de Direcciones Territoriales o Regionales, cuando los Departamentos cuenten con servicios de ámbito superior a la provincia, organizándose con independencia de las respectivas Direcciones Provinciales y bajo la autoridad del Delegado del Gobierno, y de otro lado, se admite la posibilidad de agrupación de los servicios de varios ministerios en una sola Dirección Provincial Departamental.

En ejecución de esta reforma se procedió a la supresión de las Delegaciones Provinciales, creándose en su sustitución las aludidas Direcciones Provinciales, destacándose como peculiaridades relevantes, la configuración de Direcciones Territoriales en algunos Departamentos (v.gr. Industria y Energía, por Real Decreto 3317/1981, teniendo las Direcciones Provinciales respectivas dependencia orgánica y funcional de la correspondiente Dirección Territorial), así como la agrupación de los servicios provinciales de los Ministerios de Cultura y de Educación y Ciencia en cada una de las provincias vascas y catalanas en una sola Dirección Provincial (Real Decreto 3323/1981), manteniendo, por sus propias peculiaridades las Delegaciones de Hacienda (Disposición final 2. ${ }^{\mathrm{a}}$, Real Decreto $1801 / 1981)$.

Por último, ha de hacer una obligada referencia al Real Decreto $1223 / 1983$, de 4 de mayo, que constituye el segundo escalón de la reforma iniciada, plasmando los principios recogidos en la LOAPA (después LPA), y adoptando a tal efecto como medidas más importantes la supresión de las Direcciones Provinciales en función del volumen de servicios y funciones de los respectivos Departamentos que hayan sido transferidos a las Comunidades Autónomas, adscribiéndose las unidades subsistentes de tales Direcciones suprimidas al Gobierno Civil, del que dependen orgánicamente, sin perjuicio de la dependencia funcional de su respectivo 
Ministerio; disponiendo igualmente la posibilidad de creación de Directores comisionados, cuyo análisis acometemos más adelante.

b) Disposiciones que regulan órganos específicos de caracter básico en la nueva Administración periférica estatal, centrados en la figura del Delegado del Gobierno y del Gobernador civil, así como, en un segundo plano, los Directores comisionados:

La figura del Delegado del Gobierno viene regulada por la Ley $17 / 1983$, de 16 de noviembre, en desarrollo del artículo 154 de la C.E., desarrollo ciertamente limitado por cuanto que la referida Ley se limita a reproducir el tenor del precepto constitucional, así como a regular el estatuto orgánico del Delegado del Gobierno, lo cual dota a dicha norma de una uambigüedad pretendida» para, como indica su Exposición de Motivos, «no condicionar la futura regulación de la Administración periférica del Estado».

La figura del Gobernador civil, órgano de arraigo histórico en la organización administrativa española, viene consolidada por el Real Decreto de 22 de diciembre de 1980, que configura al mismo como representante permanente del Gobierno de la Nación en la provincia, primera autoridad de la Administración civil del Estado, que ejerce su superior dirección sobre todos los servicios periféricos. Tanto a la figura del Gobernador civil como a la del Delegado del Gobierno, así como a las relaciones entre ambos, dedicaremos la última parte de este trabajo.

Por último, la institucionalización de los denominados Directores comisionados, operada por el Real Decreto 1223/1983, de 4 de mayo, ha venido a suponer una innovación relevante, de naturaleza cualitativa, en la nueva estructura periférica, derivada de la necesidad de configurar instrumentos orgánicos que ejerzan la función de coordinación interadministrativa entre el Estado y las Comunidades Autónomas, siendo características propias de estos Directores comisionados las siguientes: La encomienda preferente a los mismos de funciones de coordinación y comunicación con los órganos de las Comunidades Autónomas, sin que ello limite en modo alguno la función coordinadora general atribuida al Delegado del Gobierno; su carácter sectorial, concretado a un ámbito departamental, y dentro de las funciones que se especifiquen taxativamente; carácter eventual de su nombramiento, cuando se aprecie su necesidad, eventualidad que se justifica igualmente por la inexistencia de una estructura orgánica propia; sometimiento a la autoridad del Delegado del Gobierno, en cuanto órgano básico de coordinación. 


\section{PRINCIPALES LINEAS DE REFORMA}

Una vez analizados los criterios apriorísticos que han de inspirar la reestructuración administrativa, así como las principales reformas introducidas, procede ahora analizar cuáles son en nuestra opinión los elementos básicos en que se ha de asentar la nueva Administración periférica, una vez concluya el proceso autonómico, cuestión ésta que tropieza con los inconvenientes antes vistos e igualmente con diversos posicionamientos doctrinales que sobre el tema se han barajado.

Para proceder a este análisis conviene delimitar tres aspectos distintos aunque convergentes e intimamente relacionados: féricos.

a) La ubicación provincial o regional de los servicios peri-

b) Coexistencia y, en su caso, relaciones entre el Delegado del Gobierno y el Gobernador civil; y

c) Dependencia orgánica y funcional de las unidades o Direcciones departamentales periféricas.

\section{A) Ubicación territorial de la Administración periférica: ¿Provincialización o regionalización?}

La interpretación contextual de los artículos 141.1 y 154 de la C.E. plantea el importante problema de determinar la ubicación básica de la Administración periférica, ya que si de un lado consagra a la provincia como «división territorial básica» (art. 141.1), de otro, institucionaliza al Delegado del Gobierno como órgano regional que asume la «dirección» de dicha Administración periférica (art. 154).

Sin ánimo de buscar fórmulas absolutas en una materia que, por su propia naturaleza, ha de estar inspirada por un intenso sentido práctico, como corolario del principio constitucional de eficacia, entendemos que la ubicación territorial referida ha de venir determinada por la combinación de los siguientes principios:

1. La opción por la regionalización o la provincialización no puede llevarse con un carácter uniforme dada la diversidad cuantitativa y cualitativa de los distintos servicios periféricos estatales, tanto desde un punto de vista interdepartamental como interterritorial, pudiendo, no obstante, configurarse reglas generales, excepcionales ad hoc, de ubicación preferente.

2. En base a lo anterior, cabe señalar como regla general la provincialización de los servicios periféricos, con base a los siguientes fundamentos de orden jurídico-práctico:

REVISTA DE ESTUDIOS.-5 
a) La constitucionalización expresa de la provincia como división territorial para el cumplimiento de las actividades del Estado (art. 141.1), de lo que parece deducirse no sólo el reconocimiento de un nivel periférico de actuación más, sino la configuración de un nivel básico o preferente de ubicación territorial, lo cual no parece que pueda predicarse de la región a la vista de la indeterminación del artículo 154 de la C.E. sobre esta cuestión.

b) La ya comentada consagración constitucional del principio de desconcentración (art. 103.1 de la C.E.), que a la vista de una interpretación histórica del mismo, partiendo de la situación organizativa preconstitucional estructurada en torno a la provincia, impe diría una supuesta regionalización, con la "concentración» que ello supondría, en detrimento del nivel provincial.

c) Cabe señalar como tercera fundamentación a nuestra tesis la aplicación del principio de eficacia, cuya traducción práctica no es fácil; pero, en nuestra opinión, y en relación a la cuestión que tratamos, se plasmaría en la determinación de un nivel territorial donde se combinaran conjuntamente el acercamiento de la actuación administrativa al ciudadano $-y$, por ende, de su organizacióny la ubicación territorial coincidente del mayor número de servicios administrativos, en orden a facilitar su coordinación. Con base a ello, cabe señalar que si bien la primera nota se cumpliría mejor en una demarcación infraprovincial (v. gr. comarca, isla, municipio) y la segunda, en una ubicación regional, la combinación conjunta de ambas tiene como nivel territorial óptimo de realización el provincial.

3. La regla subsidiaria vendría determinada, por tanto, por la regionalización de los servicios periféricos de gestión, cuando su operatividad haga conveniente su ubicación regional.

4. Por el contrario, la regionalización ha de predicarse como regla preferente, en detrimento incluso de la provincia, respecto a la ubicación de servicios u órganos estatales a los que se asignan funciones de coordinación, supervisión e inspección en relación a la actividad de la Administración autonómica, con base a las siguientes consideraciones:

a) La ubicación regional del Delegado del Gobierno, prevista en el artículo 4 de la Ley 17/1983, y deducida del artículo 154 de la C.E., que, en cuanto órgano básico de coordinación, se exige que cualquier órgano o servicio periférico estatal con funciones coordinadoras o de supervisión se sitúe bajo la autoridad del Delegado del Gobierno, en base al carácter general, básico y permanente de la función coordinadora realizada por éste. En tal sentido, cabe traer a colación la importante STC de 18 de diciembre de 1984, al 
afirmar que ula coordinación de los organismos y servicios de la Administración del Estado radicados en el territorio de la Comunidad Autónoma con los de la Administración propia y peculiar de la Comunidad Autónoma deberá siempre llevarse a cabo con la intervención de la Delegación del Gobierno en la Comunidad Autónoma».

b) La ubicación regional de los centros directivos de la Administración autonómica, lo que evidencia la necesidad de una situación territorial paralela, por regla general, de los órganos estatales de coodinación o interrelación.

En consecuencia, cabe sostener la primacía de la provincialización en cuanto a la ubicación de los órganos o servicios estatales periféricos de gestión, así como los de su coordinación (coordinación intraadministrativa), prevaleciendo, por el contrario, el nivel regional en cuanto a los órganos de relación interadministrativa con la Administración autonómica.

Sin embargo, cabe analizar cuál es el alcance de la provincialización, esto es, determinar los requisitos que han de darse para que pueda hablarse de la provincialización de la Administración periférica, cuestión que en nuestra opinión se concreta en la concurrencia de los siguientes elementos:

En primer lugar, y siguiendo a Guaita, la provincialización exige que la provincia se convierta en «territorio», concepto jurídico, en cuanto infraestructura física, materialización de la competencia de un órgano, acotando la competencia territorial de dicho órgano. Por lo tanto, en este aspecto la provincialización implica que los órganos periféricos, sectoriales y generales limiten su competencia, por regla general, exclusivamente al ámbito provincial,

En segundo lugar, ha de exigirse, en nuestra opinión, que la coordinación intraadministrativa de dichos órganos provinciales se lleve a efecto igualmente por un órgano situado en el mismo nivel provincial, pues sólo así se consigue la unidad de la actuación administrativa periférica a nivel provincial, mediante una dirección unitaria en dicho escalón territorial.

\section{B) Coexistencia y relación entre el Delegado del Gobierno y el Gobernador civil}

Sin duda alguna, la cuestión más debatida política como doctrinalmente en relación a la reestructuración administrativa derivada del proceso automático se centra en la subsistencia de los Gobernadores civiles, con sus atribuciones actuales en el nuevo mapa organizativo. La cuestión se ha centrado básicamente en la 
utilidad y eficacia de esta figura histórica, de relevante contenido político, ante la institucionalización de los Delegados del Gobierno, en cuanto órganos igualmente políticos y de competencia general.

Con carácter previo al análisis de esta cuestión en nuestro ordenamiento vigente, entendemos conveniente realizar una breve reseña sobre la plasmación de situaciones de similar coexistencia en sistemas comparados $y$ en antecedentes patrios.

A nivel comparado, debemos centrar nuestro estudio en el sistema italiano, al haber servido la figura del Comisario del Gobierno instaurada en aquel pais, de fuente inspiradora del artículo 154 de nuestra Constitución, cuya similitud con el artículo 124 de la Constitución italiana es evidente. En tal sentido, cabe reseñar la coexistencia del Comisario del Gobierno con la figura del Prefecto provincial, atribuyéndose al primero la dirección y supervisión de las funciones administrativas del Estado en el ámbito regional, funciones éstas que, según Vandelli no implican de modo alguno relación de jerarquía, stricto sensu entre ambas instancias. Igualmente cabe resaltar, tras la innovación administrativa operada en Francia, la coexistencia en dicho país de las figuras del Prefecto y del llamado representante del Estado en la región, aunque entendemos que no es exactamente trasladable, comparativamente, al actual sistema español.

En cuanto a los precedentes históricos españoles no han sido pocos los intentos, aunque con escaso éxito, de situar conjuntamente órganos generales representantes del poder central a nivel provincial y regional, pudiendo agrupar tales precedentes en los siguientes grupos:

a) Sistemas que configuraban un órgano regional de competencia general, pudiendo incluirse aquí, entre otros, los siguientes precedentes:

La llamada «Reforma de Escosura» (plasmada en el Real Decreto de 29 de septiembre de 1847, suspendida por Real Decreto de 5 de octubre del mismo año). Se centraba básicamente en la división del territorio nacional en once Gobiernos Generales, a cuyo frente se situaba un Gobernador civil general, ubicando en cada provincia un Gobernador civil, cuyas funciones ejercía en su sede el Gobernador general, atribuyéndose al mismo la jefatura de la Administración Civil, siendo conducto ordinario de los Ministerios de Gobernación, Hacienda, Obras Públicas, Industria e Instrucción, correspodiéndole igualmente la inspección y dirección de los Gobernadores civiles, así como la resolución de recursos de órganos inferiores.

"Proyecto Moret» (de 5 de enero de 1884). Concebía la división del territorio en quince regiones, situando al frente de las mismas 
un Gobernador en cuanto representante superior del Gobierno en el orden político y administrativo y superior jerárquico del llamado «Delegado provincial», ubicado en cada provincia. En dicho proyecto se indicaba expresamente que el Delegado provincial «desciende de rango», otorgándole el carácter puramente administrativo, "de modo que la política se aleje de estos funcionarios y vaya a gravitar en los quince grandes centros, bajo la dirección del Gobernador civil».

«Proyecto de Sánchez Toca» (1891). Prevé la creación de trece regiones, situando en cada una de ellas a un Gobernador regional, jefe inmediato de los Gobernadores civiles comprendidos en las provincias ubicadas en la circunscripción regional.

Estatuto provincial de Calvo Sotelo (Real Decreto de 20 de marzo de 1925), que asigna la representación del gobierno a los Gobernadores regionales y a los Subgobernadores en provincias.

b) Antecedentes que prevén la existencia de representantes gubernamentales regionales o supraprovinciales, con competencias sectoriales. Cabe citar fundamentalmente: Los Gobernadores civiles generales, previstos en el Decreto de 10 de octubre de 1958; Delegados especiales, previstos en el artículo 6 del Estatuto de Autonomía de Cataluña de 1932, y artículo 6 de la Ley sobre el Estatuto Vasco de 1936. El Comisario general de Orden Público para Cataluña (1933), entre otros muchos supuestos, cuya enumeración detallada obviamos.

Retomando el análisis de la coexistencia entre los Delegados del Gobierno y los Gobernadores civiles en la culminación final de la reestructuración administrativa española, entendemos que tal coexistencia no sólo es plenamente factible, sino además necesaria, con base en los siguientes fundamentos:

1. Las figuras del Delegado del Gobierno y del Gobernador civil, a pesar de su identificación como órganos políticos de competencia general, en nuestra opinión no constituyen escalas superpuestas que permitan deducir la innecesariedad del Gobernador civil en cuanto órgano de dirección de la Administración periférica, en base al reconocimiento de dicha función al Delegado del Gobierno. Entendemos, por el contrario, que ambas figuras están llamadas a ejercir dos funciones distintas, aunque convergentes entre sí, tal como a continuación intentaremos exponer:

a) El artículo 154 de la Constitución institucionaliza la figura del Delegado del Gobierno, colocando en una posición aparente de paridad las funciones de dirección de la Administración del Estado y la de coordinación entre ésta y la administración autonómica; sin 
embargo, y tal como en su día expusimos en nuestro trabajo sobre «La función coordinadora interadministrativa de los Delegados del Gobierno en las Comunidades Autónomas», tal posición de paridad no es real, debiendo prevalecer, al amparo del texto constitucional, la función coordinadora al mismo atribuida, en base a la ubicación sistemática de dicho precepto, contenido en el título VIII de la C.E. ("Organización territorial del Estado»), capítulo III («De las Comunidades Autónoması), con lo que ha de entenderse que el Constituyente, al optar por regular tal figura en dicho título y no en el título IV («Del Gobierno y de la Administración»), ha enfatizado el protagonismo del Delegado del Gobierno en cuanto pieza básica del Estado autonómico, en el que adquiere especial protagonismo en base a la función coordinadora que se le atribuye. Este predominio de la función coordinadora se deduce aún más claramente de la situación del precepto citado, intermedia entre los artículos 153 y 155, que delimitan las fórmulas de control de la actividad de las Comunidades Autónomas. En consecuencia, y tal y como expusimos en su día, el Delegado del Gobierno, en cuanto órgano básico de coordinación interadministrativa, ostenta la condición de institución básica del Estado, configurado como elemento estructural básico, necesario y permanente de la organización jurídico-pública estatal.

b) Por el contrario, entendemos que la función directiva de la Administración periférica que el propio artículo 154 reconoce al Delegado del Gobierno, si bien tiene una relevancia indudable, ha de venir, en nuestra opinión, delimitada dentro de ciertos márgenes, que se concretan en los siguientes:

La dirección de la Administración periférica regional ha de concebirse sustancialmente como función instrumental encaminada a facilitar la función coordinadora encomendada, por cuanto que no es factible la coordinación de una Administración con otra, si no se ostenta un poder de supervisión y dirección sobre la organización que se pretende coordinar.

La función de dirección no cabe entenderla, tal como se desprende de la Ley 17/1983, como una dirección jerárquica, por regla general, salvo excepciones, tal como se deduce de los términos utilizados en dicha norma, que utiliza las expresiones de "coordinación» (intraadministrativa), "superior autoridad sobre todos los órganos de la Administración periférica», "posición de supremacía» sobre los mismos. De toda esta terminología y siguiendo a la doctrina administrativa, ha de distinguirse entre «jerarquía» y «supremacía», caracterizándose la supremacía porque implica una posición habilitante de la dirección de la actuación de los órganos inferiores, pero no alcanza una intensidad capaz de 
provocar en éstos una vinculación jerárquica, dándose asi una situación de poder de unos órganos sobre otros, poder de dirección que no va acompañado, como afirma Parejo Alfonso, del resto de las potestades que caracterizan la posición típica del superior jerárquico, faltando el poder de control sobre los actos del inferior. En consecuencia, cabe entender que la posición del Delegado del Gobierno se enmarca dentro de una situación de supremacia, en el sentido expuesto, cuya realización efectiva debería instrumentarse a través de la Comisión de coordinación de carácter regional.

2. Por su parte, el Gobernador civil, además de las funciones propias en materia de Interior, ha de protagonizar, entendemos, la función directiva efectiva sobre los servicios periféricos administrativos situados a nivel provincial, ubicación territorial básica, concretándose las funciones del Gobierno Civil en función de la intensidad competencial de los distintos servicios departamentales, una vez culminado el proceso autonómico, distinguiendo así:

a) En general, respecto a todos los servicios periféricos, el Gobernador asumiría la función de coordinación efectiva de los mismos, sin perjuicio de la coordinación regional a realizar por el Delegado del Gobierno.

b) En cuanto a los servicios periféricos departamentales no integrados en una Dirección Provincial, entendemos que procede su adscripción y dependencia, no sólo orgánica, sino también funcional, del respectivo Gobierno Civil, asumiendo el Gobernador su dirección efectiva, convirtiéndose, en consecuencia, en instancia administrativa provincial; incrementando las competencias administrativas que en este momento ostenta.

c) Por el contrario, los servicios integrados en Direcciones Provinciales que subsistan mantendrán su actual dependencia funcional de sus respectivos Ministerios, aunque siempre sometidos a la coordinación a desempeñar por el Gobierno Civil.

d) En todo caso, el Gobernador civil ha de seguir ostentando las funciones que en la actualidad le encomienda el ordenamiento jurídico en materia de orden público y seguridad ciudadana, así como las demás funciones de Interior.

En consecuencia, la figura del Gobernador civil está llamada a ejercer una función esencial en la futura organización administrativa española, en cuanto unidad administrativa provincial básica, siendo preciso, no obstante, su remodelación, incrementando sus competencias propiamente administrativas, pero sin perder su actual condición política, con lo cual se consiguen los siguientes objetivos: 
- Potenciar la función coordinadora interadministrativa de los Delegados del Gobierno, en el que se centralizaría tal función, dependiendo directamente del mismo todo servicio estatal periférico departamental que asuma competencias de supervisión, inspección o coordinación de la actuación autonómica.

- Concentrar la dirección administrativa de las unidades periféricas de gestión en el nivel provincial, bajo la figura del Gobernador civil y del Delegado del Gobierno, éste último respecto a los servicios situados en la sede de la Delegación, sean tanto de competencia regional como provincial.

- Mantener la posición de supremacía y coordinación del Delegado del Gobierno sobre la totalidad de la Administración periférica regional, entendiendo dicha supremacía, como ya expusimos, no en un sentido de dirección jerárquica (que puede no obstante darse en supuestos específicos y para determinadas situaciones).

- Plasmar la provincialización exigida por la Constitución, sin detrimento del necesario protagonismo que viene a asumir el «escalón regional».

\section{C) Configuración de las unidades departamentales periféricas}

Siguiendo el esquema prefijado, nos resta, por último, examinar cuál ha de ser la configuración de las unidades departamentales periféricas que subsistan una vez culminado el proceso autonómico; cuestión ésta que ya viene deducida del estudio y exposición de los elementos anteriores y que podemos concretar en las siguientes notas:

1. Estructuración de los servicios periféricos departamentales en función del volumen de servicios y funciones que subsistan, cumpliendo así los principios contenidos en la Ley de Proceso Autonómico, subsistiendo las Direcciones Provinciales sólo respecto a aquellos Departamentos ministeriales que mantengan un amplio nivel de competencias periféricas.

2. La dependencia orgánica y funcional habrá de determinarse en función del citado volumen competencial subsistente, distinguiendo así:

- Las Direcciones Provinciales departamentales que subsistan habrán de mantener la dependencia funcional de su respectivo Ministerio por exigencia de la especialidad funcional que el volumen de competencias que mantienen determina. 
- Las unidades administrativas no integradas en Direcciones Provinciales pasarían a depender orgánica y funcionalmente del Gobernador civil o del Delegado del Gobierno, en los términos antes vistos.

- Los servicios administrativos departamentales que carezcan de estructura orgánica periférica propia serían asumidos por los Gobernadores civiles o Delegados del Gobierno, en función de la materia y ámbito territorial de actuación.

3. La ubicación territorial dependerá de las necesidades prácticas concurrentes, prevaleciendo el escalón provincial en cuanto a las unidades con competencias de gestión, y el nivel regional en cuanto a los servicios de coordinación, supervisión e inspección en relación con las actividades administrativas autonómicas. 
REALA-1989, núm. 244. OROZCO MUÑOZ, MARTIN. LA ADMINISTRACION PERIFERICA EN EL E... 
REALA-1989, núm. 244. OROZCO MUÑOZ, MARTIN. LA ADMINISTRACION PERIFERICA EN EL E...

II. CRONICAS

REALA-1989, núm. 244. OROZCO MUÑOZ, MARTIN. LA ADMINISTRACION PERIFERICA EN EL E... 
